\title{
Proposal for Prioritizing the Retrofitting of Residential Buildings in Energy Poverty Circumstances
}

\author{
Silvia PEREZ-BEZOS ${ }^{1 *}$, Olatz GRIJALBA ${ }^{2}$, Olatz IRULEGI ${ }^{3}$ \\ ${ }^{1-3}$ CAVIAR Research Group, Department of Architecture, University of the Basque \\ Country (UPV/EHU), Plaza Oñati, 2, 20018 Donostia - San Sebastián, Spain
}

\begin{abstract}
The energy poverty derived from socio-economic imbalances affects mostly households with fewer economic resources, being social housing complexes one of the most vulnerable sectors. The insufficient access to energy and the incapability to maintain dwellings at an adequate temperature can have negative impact on people's health due to the prolonged exposure to poor hygrothermal conditions. Therefore, the prioritization of building retrofitting actions must be carried out regarding the actual state of the housing and the family economy. This paper proposes the definition of a prioritization map that gave a general knowledge of the energy vulnerability situation of the existing building stock. To this end, the dwelling's energy performance is analysed, focusing on the correlation among its characteristics and the energy vulnerability of its inhabitants. In this way, dwellings with high energy poverty potential are identified in order to develop different energy retrofitting strategies. By applying this method to 14 case studies of social housing in Bilbao, Spain, it was obtained a prioritization map with six levels of vulnerability that can serve as a tool for public entities to design their future strategies. It has been proven that building compactness and year of construction are important factors with a great impact on the heating demand and final consumption in dwellings. Acknowledging the vulnerability context of the building stock eases the decision-making process and the definition of intervention guidelines, prioritizing those in a situation of greater vulnerability.
\end{abstract}

Keywords - Building energy renovation; energy poverty; low income households; social housing; thermal performance

\begin{tabular}{|lll}
\hline Nomenclature & & \\
$U_{\text {wall }}$ & Wall thermal transmittance & $\mathrm{W} / \mathrm{m}^{2} \mathrm{~K}$ \\
$U_{\text {win }}$ & Window thermal transmittance & $\mathrm{W} / \mathrm{m}^{2} \mathrm{~K}$ \\
$U A$ & Heating demand & $\mathrm{kWh} / \mathrm{m}^{2} \mathrm{y}$ \\
$S f$ & Shape Factor & $\%$ \\
$S c$ & Shape Coefficient & $\mathrm{m}^{2} / \mathrm{m}^{2}$ \\
\hline
\end{tabular}

* Corresponding author.

E-mail address: silvia.perezb@ehu.eus 


\section{INTRODUCTION}

\subsection{Background}

There is a socio-economic imbalance which mostly affects households with fewer economic resources, being social housing complexes one of the most vulnerable sectors. The insufficient access to energy and the incapability to maintain dwellings at an adequate temperature [1] results into energy poverty, which depends on three main factors [2]:

- Energy cost;

- Low incomes;

- Low energy efficiency of dwellings.

A prolonged exposure to poor hygrothermal conditions in dwellings can have negative impact on people's health. Consequently, there is a high correlation between inadequately heated or low indoor temperatures and Excess Winter Death rates [3] (EWD), which is also strongly linked to high poverty rates, inefficient building stock and high energy costs [1]. Building deficiencies and the difficulty or high cost of its refurbishment affect respiratory and cardiovascular health during winter periods, while high indoor temperatures may cause diseases and increase mortality due to cardiovascular causes [4].

There are two widely recognised measurement approaches for energy poverty assessment [5]: household income/expenditure-based indicators [6], [7], and consensual indicators based on responses to material deprivation questionnaires [8]. The challenge with these measurement approaches lies in the source of data used for the analysis. In most cases the expenditure gathered in the Household Budget Surveys of each country's statistical offices is taken for reference [9], however, as many households limit their energy consumption to meet other needs, the indicators may not reflect the real energy demand. Sánchez-Guevara [10] developed an energy poverty methodology based on minimal thermal habitability conditions that gathers climatic, building and socioeconomic particularities of the country. The method is focused on the energy expenditure required to achieve minimal thermal habitability conditions in low income dwellings.

Several studies analysing the relationship between energy poverty and monetary poverty suggest that low-income households are at greater risk of being in a situation of energy vulnerability [11], [12]. In this context, there has been a steady rise in the expenses/income ratio in Spanish households related to the increase in household energy consumption per family unit and per person between 2006 and 2012, according to the 2018 Energy Poverty Report [9].

One of the measures to alleviate this situation is the energy social subsidy, however, several authors propose housing renovation and energy efficiency improvement as an appropriate measure to reduce energy poverty [13], [14], with an improvement of the building hygrothermal performance. Increasing building's energy efficiency and reducing dwelling's primary energy consumption can play an important role in governments' energy targets [15].

Among the large amount and variety of buildings with potential for energy improvement, social housing complexes are notable case where refurbishment is a priority due to the socioeconomic vulnerability of its residents. There are several difficulties in defining intervention strategies in these buildings, requiring a quantitative method of analysis to assess the needs of these households.

This research extends its scope to the city of Bilbao, north of Spain, as the architectural and construction typologies analysed are those representatives of a city, and hence, the conclusions can be extrapolated to other cities and countries. Acknowledging the 
vulnerability context of the building stock eases the decision-making process and the definition of intervention guidelines, prioritising those in a situation of greater vulnerability.

\subsection{Objectives}

This paper proposes the definition of a prioritization map that gives a general knowledge of the energy vulnerability situation of the existing building stock. To this end, the dwelling's energy performance is analysed, focusing on the correlation among its characteristics and the energy vulnerability of its inhabitants. In this way, dwellings with high energy poverty potential are identified in order to develop different energy retrofitting strategies. To achieve the main objective of the research, the following objectives are attained:

- identifying the physical parameters of the building that influence dwelling's heating demand. The study focuses on the passive aspects and does not include active conditioning systems;

- analysing the level of impact of the characteristics of buildings on the heating consumption and demand;

- determining to what extent the heating demand can be, along with the income and the price of energy, an indicator for evaluating the degree of vulnerability of a household.

In addition to the prioritization map, two partial results are obtained: annual heating demand and cost calculation model and adapted energy poverty assessment for the case of Bilbao and the Autonomous Community of the Basque Country.

\section{APPROACH}

\subsection{Energy Poverty Assessment}

Energy vulnerability assessment is based on the energy poverty assessment graph proposed by Sánchez-Guevara [10], according to income/expenditure-based indicators, which incorporates the climatic, building and socioeconomic characteristics of the country and the region in the analysis. The method includes monetary and fuel poverty indicators:

- monetary poverty: based on the Eurostat methodology, where the poverty threshold is defined as $60 \%$ of the median household income;

- energy poverty: following the trend of studies and first proposed by Boardman [6], it takes $10 \%$ of income as the monetary poverty threshold and sets $20 \%$ as severe energy poverty and $5 \%$ as vulnerability to energy poverty [10], as it follows:

$$
\frac{\text { Energy consumption } \cdot \text { Energy cost }}{\text { Income }}>10 \%
$$

Since we only want to consider heating cost for energy vulnerability assessment, it is necessary to set the appropriate percentage for the threshold, as Sánchez-Guevara [10]. In Fig. 1 the one on the left represents the starting model, where the dwelling's total energy expenditure is considered. The one on the right shows one of those defined by SánchezGuevara for the Mediterranean climate, where the annual heating and cooling expenditure is considered. 

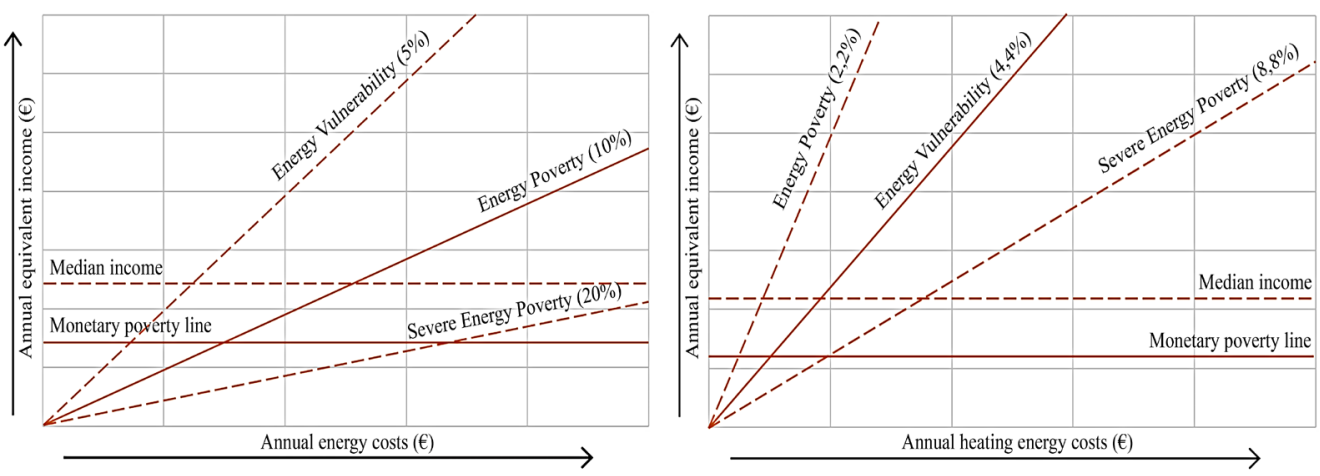

Fig. 1. Energy poverty assessment for total energy expenditure (left), and Energy poverty assessment for the Mediterranean climate (right) [10].

\subsection{The Influence of Building Characteristics on Heating Demand}

The thermal performance of a building depends on various parameters that can be classified into two major groups: design-physical factors of the environment and occupation factors [16] that have an effect on energy use of a $42 \%$ and $4.2 \%$, respectively [17]. After considering these values, it was decided to analyse the environmental and design parameters to evaluate the impact of the building characteristics and demand on the energy vulnerability of households.

Bektas et al. [18] summarizes the parameters that affect building's thermal performance: physical and environmental parameters (outdoor temperature, solar radiation and wind direction and speed) and design parameters (shape factor, transparent/opaque surface, orientation, thermal properties of building materials, and distance between buildings).

Building envelope characteristics have a direct effect on the thermal performance. Within these parameters, the ratio between transparent and opaque surface represents an impact of $20 \%$ on the cooling demand and $11 \%$ on heating demand [19].

The shape of the building influences the amount of solar radiation it receives and its energy consumption, in particular, Elasfouri et al. [20] suggested that the radiation reaching the building can increase the cooling demand by up to $25 \%$. Depecker et al. [21] defined the relationship between building shape and energy demand, and concluded that for cold climates energy consumption is proportional to compactness $\left(\mathrm{m}^{3} / \mathrm{m}^{2}\right)$. A correct combination of the shape factor (ratio of length to depth of the building) and orientation can result in $36 \%$ energy savings [22].

Several studies have investigated the relationship between urban compactness and access to the sun of urban areas [23], [24]. Salvati et al. [25] suggested that an increase in density in certain urban areas can lead to an increase in heating demand due to a decrease in solar radiation. However, for densities above $40 \%$, the intensity of the heat island effect is greater than the reduction in solar radiation. These parameters evidence the importance of building design for energy saving, by applying passive design solution and using right materials and design tools [26]. 


\section{METHODS AND METHODOLOGY}

The method is divided in three stages. In the first stage, an adaptation of the energy poverty assessment method was made, which relates the equivalent heating cost to the equivalent annual income of the household. In the second stage, the influence of the physical characteristics of the buildings on the heating demand is analysed, with energy simulations and theoretical results from previous studies. Finally, 14 case studies are evaluated in order to spot possible cases of energy vulnerability and necessity of intervention, and compared in a prioritisation classification.

\subsection{Adjusting the Energy Poverty Assessment}

Sánchez-Guevara's [10] energy poverty assessment measurement parameters include the particularities of each location. Therefore, a specific adjustment was required for the case of Bilbao and the Autonomous Community of the Basque Country (CAPV).

Firstly, the energy poverty threshold was adjusted, as the $10 \%$ of the total income estimated to cover the energy needs of a household. Table 1 refers to total expenditure per household $(€)$ and includes consumption associated with sanitary hot water, lighting and domestic appliances. In the energy vulnerability assessment, only the energy consumption for heating is considered, so it is necessary to set an appropriate percentage for the threshold, as SánchezGuevara exposed [10]. To this end, energy consumption in dwelling was determined by equipment and energy source, using data from the Basque Country on household energy consumption according to the SPAHOUSEC project, carried out by the "Instituto para la Diversificación y Ahorro de la Energía" (IDAE) [27].

Subsequently, the energy expenditure of the dwelling was calculated based on the state energy price, as shown in Table 1. The energy consumption and expenditure were calculated using the following data:

- Dwelling energy consumption;

- Domestic hot water (DHW), heating and cooking systems, by energy source;

- Energy costs;

- Dwelling energy expenditure;

- Heating expenditure.

The percentage of heating expenditure determines the energy poverty threshold. This value was calculated using energy price from Eurostat. The results established an energy poor household when the expenditure on heating was higher than $3.4 \%$ of the income.

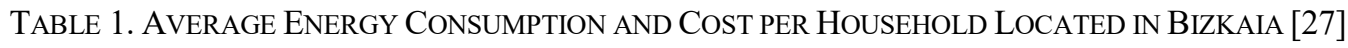

\begin{tabular}{lcccc}
\hline Final use & $\begin{array}{c}\text { Energy } \\
\text { Consumption, kWh }\end{array}$ & $\begin{array}{c}\text { Energy } \\
\text { Consumption, \% }\end{array}$ & Energy Costs, $€$ & Energy Costs, \% \\
\hline Heating System & 4142.73 & 40.10 & 659.62 & 33.59 \\
Domestic Hot Water & 2262.49 & 21.90 & 288.19 & 14.68 \\
Cooking Systems & 1239.72 & 12.00 & 271.78 & 13.84 \\
Cooling Systems & 10.33 & 0.10 & 2.86 & 0.15 \\
Lighting & 392.58 & 3.80 & 108.74 & 5.54 \\
Electrical appliance & 2283.15 & 22.10 & 632.43 & 32.21 \\
Total & 10331.00 & 100.00 & 1963.62 & 100.00 \\
\hline
\end{tabular}


The monetary poverty threshold was calculated according to Sánchez-Guevara [10], as $60 \%$ of the median income according to Eurostat methodology. Afterwards, data was taken from the Household Budget Survey [28] defined for each autonomous community. The average income for Bilbao was taken as the monetary poverty threshold. The monetary poverty values and the energy poverty thresholds were then transferred to the energy poverty assessment graph, adapted for the case of Bilbao.

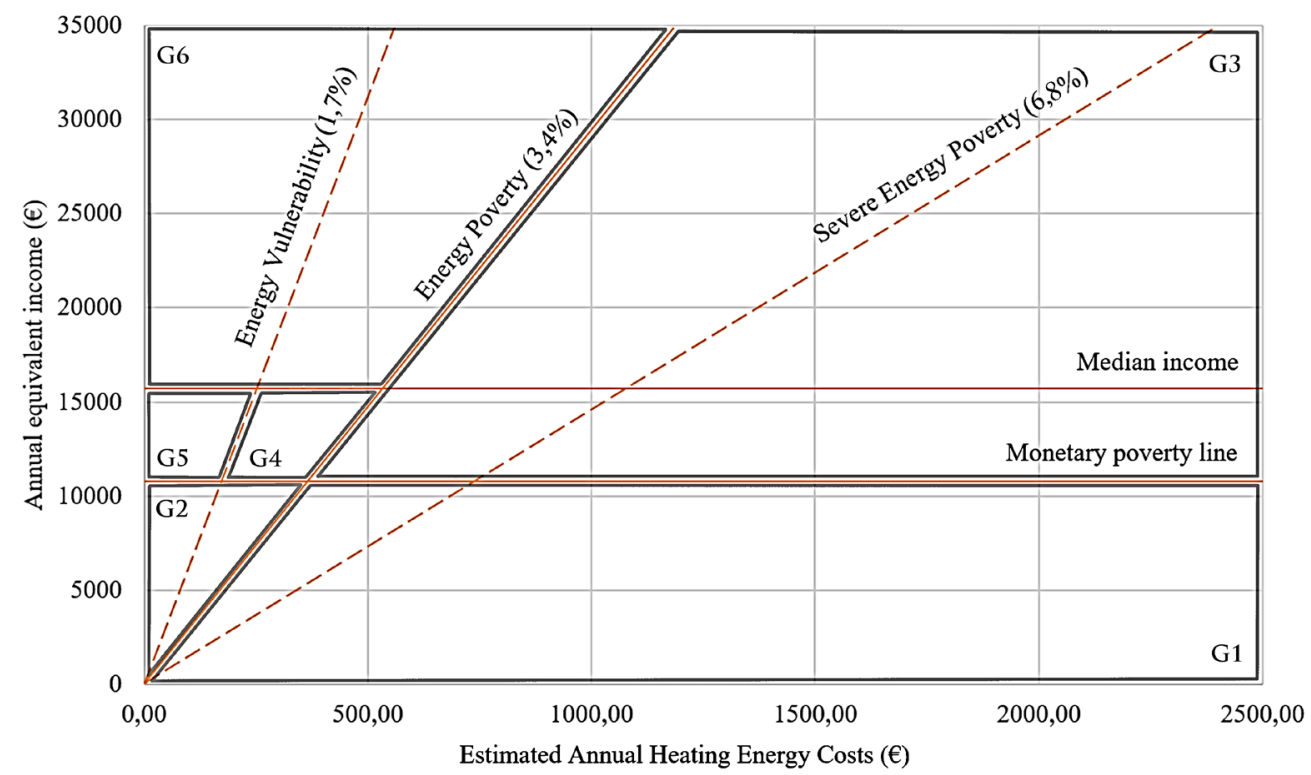

Fig. 2. Energy Poverty Assessment model for Bizkaia, based on the energy poverty methodology proposed by Sánchez-Guevara [10].

Once the method has been adjusted to the location chosen for the study, it is possible to develop the energy poverty assessment with household's annual income and heating costs data, as shown in Fig. 2. According to their ubication in the graph, analysed cases were classified in groups with lower or higher fuel poverty vulnerability. Groups G1, G2 and G3 represent those who are under some type of poverty, while groups G4 and G5 are determined by those groups that, despite not being in a situation of poverty, are in a vulnerability condition due to their proximity to the poverty threshold. Group G6 is considered to be outside any type of poverty or vulnerability.

\subsection{Annual Heating Demand and Cost Calculation Model}

In the second phase of the study, the influence of the physical characteristics of the buildings was analysed, considering the key aspects that determine their energy performance. Bilous et al. [29] concluded that the variables that have the greatest influence on indoor temperature are from highest to lowest: air exchange rate, heating gains, outdoor temperature and solar gains. Considering that air exchange and heating gains are highly user-dependent, they were not considered for the study. Instead, outdoor temperature and solar gains were considered as project variables, related to the following parameters:

- Urban Density, \%; 
- Building compactness or Shape Coefficient, $\mathrm{m}^{2} / \mathrm{m}^{3}$;

- Shape Factor, \%;

- Orientation;

- Construction characteristics $(U), \mathrm{W} / \mathrm{m}^{2} \mathrm{~K}$.

The first three parameters were analysed considering the theoretical results of previous research, while the impact of orientation and construction characteristics were determined carrying out energy simulations developed with the Design Builder program, with the Energy Plus database.

The impact of Urban Density, Shape Coefficient and Shape Factor on building's thermal energy demand was analysed based on the results of previous studies, explained in the subchapter 2.2. The Influence of Building Characteristics on Heating Demand.

Possible future research would focus on the analysis of user behaviour in heating consumption. Jimenez-Bescos et al. [30] concluded that incorporating user behaviour into building simulations, a more accurate estimation of energy consumption could be achieved.

The reference volume used for the energy simulations was defined as a linear block typology, as it is a construction type widely used in urban areas, both in Bilbao and in Spain in this type of social housing. The model has a shape factor of $2 / 1$ with 5 floors and ground floor with a north-south orientation of its longitudinal face. It has $378 \mathrm{~m}^{2}$ footprint, $54 \mathrm{~m}$ length and $7 \mathrm{~m}$ width. The total height of the block is $15 \mathrm{~m}$, and each floor has $2.5 \mathrm{~m}$ height. The shape coefficient of the building is $2.9 \mathrm{~m}^{2} / \mathrm{m}^{3}$ with an urban density of $0 \%$.

A characterization of the construction systems used in the existing building stock was also carried out (walls' and windows' thermal transmittance and percentage of openings in the facade), following Terés' [31] and “Caracterización del parque residencial de la CAPV para la elaboración de un plan de acción a largo plazo” [32] study’s results, as shown in Table 2.

TABLE 2. ENClosure CHARACTERIZATION OF THE BUILDING PARK, BASQUE COUNTRY

\begin{tabular}{cccccc}
\hline $\begin{array}{c}\text { Construction } \\
\text { year }\end{array}$ & Period & $\boldsymbol{U}_{\text {wall }}, \mathbf{W} / \mathbf{m}^{\mathbf{2}} \mathbf{K}$ & $\boldsymbol{U}_{\text {win }}, \mathbf{W} / \mathbf{m}^{\mathbf{2}} \mathbf{K}$ & $\begin{array}{c}\text { Window } \\
\text { percentage, } \%\end{array}$ & $\begin{array}{c}\text { Heating demand } \\
\text { model, } \mathbf{k W h} / \mathbf{m}^{\mathbf{2}} \mathbf{y}\end{array}$ \\
\hline Before 1900 & 1 & 1.11 & 4.23 & 0.1 & 46.69 \\
$1901-1940$ & 2 & 1.11 & 4.84 & 0.31 & 47.45 \\
$1941-1960$ & 3 & 1.16 & 4.62 & 0.21 & 46.93 \\
$1961-1966$ & 4 & 1.44 & 4.62 & 0.34 & 49.69 \\
$1967-1980$ & 5 & 1.44 & 5.7 & 0.34 & 54.36 \\
$1981-2006$ & 6 & 0.48 & 4.16 & 0.24 & 37.11 \\
After 2006 & 7 & 0.41 & 2.76 & 0.22 & 31.28 \\
\hline
\end{tabular}

Note: The thermal transmittance of the roof is taken as a constant value as it requires an exhaustive specific study

A total of 28 simulations were carried out, in which the construction year and thus the construction characteristics were modified, as well as the orientation of the building in relation to the longitudinal facades: $0^{\circ}$ (north-south), $45^{\circ}$ (northeast-southwest), $90^{\circ}$ (eastwest) and $135^{\circ}$ (northwest-southeast). 


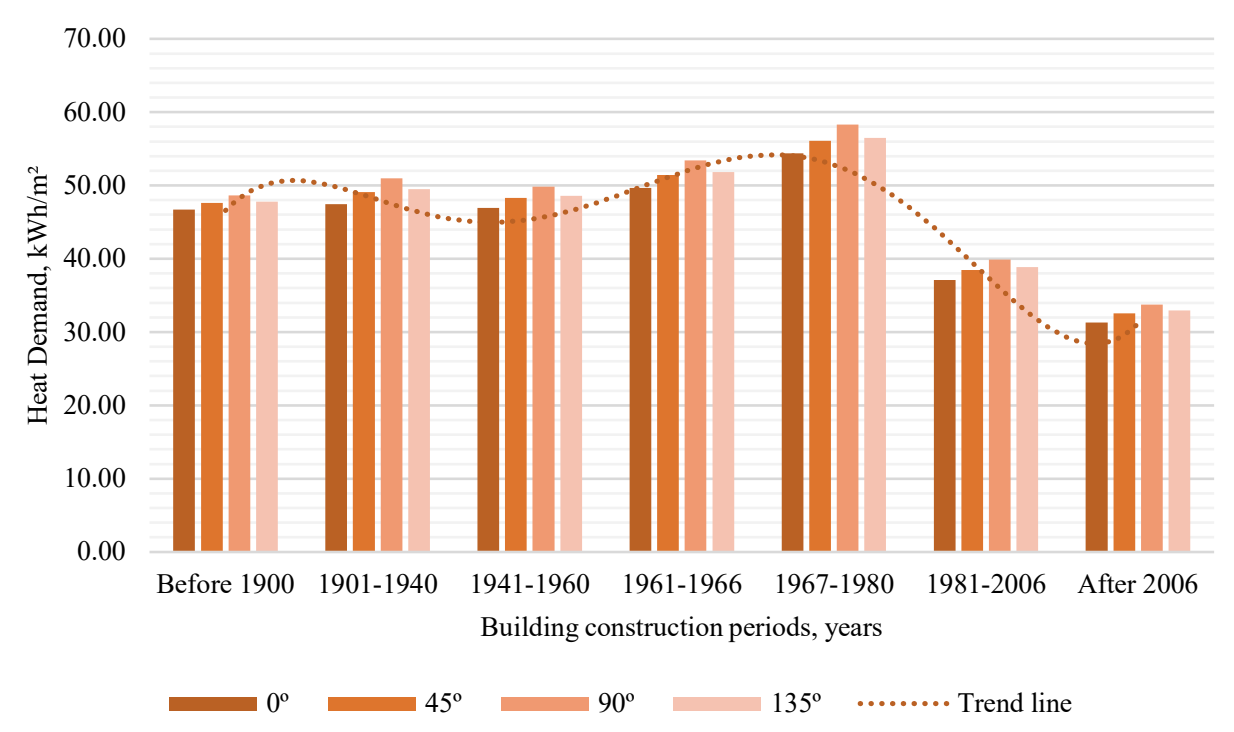

Fig. 3. Heating demand variation according to the building orientation and construction period characteristics.

The main results of the simulation showed that the cases with the greatest demand were those where the reference building was located in an east-west orientation, and specifically, the most unfavourable period corresponded to buildings constructed between 1967 and 1980, shown in Fig. 3.

Based on the influence and impact of the building's physical parameters on the energy heating demand, a method to estimate the dwelling heating demand and annual heating costs has been defined.

The method takes as a starting point the heating demand model $\left(\mathrm{kWh} / \mathrm{m}^{2} \mathrm{y}\right)$ obtained from the simulations in Table 2, to which the savings of each physical parameter of the building are added or deducted. The data of savings is collected in Table 3, Table 4. Once the building's heating demand $\left(\mathrm{kWh} / \mathrm{m}^{2} \mathrm{y}\right)$ is known, a sample dwelling is taken from it and the estimated heating demand ( $\mathrm{kWh} / \mathrm{y})$ and cost $(€ / \mathrm{y})$ is determined, applying Eq. (2), Eq. (3) and Eq. (4).

Heating Demand $\left(\frac{k W h}{m^{2} y}\right)=$ Heating Demand Model $\left(\frac{k W h}{m^{2} y}\right) \cdot\left[1-\sum\right.$ Energy Conservation (\%) $]$

Estimated Heating Demand $\left(\frac{k W h}{m^{2} y}\right)=$ Heating Demand $\left(\frac{k W h}{m^{2} y}\right) \cdot$ Dwelling area $\left(\mathrm{m}^{2}\right)$

Estimated Heating Cost $\left(\frac{\text { EUR }}{y}\right)=$ Estimated Heating Demand $\left(\frac{k W h}{y}\right) \cdot$ Energy Costs $\left(\frac{\mathrm{EUR}}{k W h}\right)$ 
TABle 3. SAVINGS In HeAting Demand Relative to ORIENTATION $0^{\circ}$ (N-S) FOR THE DIFFERENT CONSTRUCTION PERIOD

\begin{tabular}{|c|c|c|c|c|c|c|c|c|}
\hline \multirow{3}{*}{ Stage } & \multicolumn{8}{|c|}{ Orientation } \\
\hline & \multicolumn{2}{|c|}{$0^{\circ}(\mathrm{N}-\mathrm{S})$} & \multicolumn{2}{|c|}{$45^{\circ}$ (NE-SW) } & \multicolumn{2}{|c|}{$90^{\circ}(E-W)$} & \multicolumn{2}{|c|}{$135^{\circ}(\mathrm{NW}-\mathrm{SE})$} \\
\hline & Sf $1 / 1$ & Sf $2 / 1$ & Sf $1 / 1$ & Sf $2 / 1$ & Sf $1 / 1$ & Sf $2 / 1$ & Sf $1 / 1$ & Sf $2 / 1$ \\
\hline 1 & $3.67 \%$ & 0 & $1.74 \%$ & $-1.93 \%$ & $-0.52 \%$ & $-4.19 \%$ & $1.63 \%$ & $-2.31 \%$ \\
\hline 2 & $3.67 \%$ & 0 & $0.22 \%$ & $-3.45 \%$ & $-3.74 \%$ & $-7.41 \%$ & $-0.62 \%$ & $-4.29 \%$ \\
\hline 3 & $3.67 \%$ & 0 & $0.77 \%$ & $-2.90 \%$ & $-2.47 \%$ & $-6.14 \%$ & $0.13 \%$ & $-3.54 \%$ \\
\hline 4 & $3.67 \%$ & 0 & $0.14 \%$ & $-3.53 \%$ & $-3.83 \%$ & $-7.50 \%$ & $-0.68 \%$ & $-4.35 \%$ \\
\hline 5 & $3.67 \%$ & 0 & $0.52 \%$ & $-3.15 \%$ & $-3.56 \%$ & $-7.23 \%$ & $-0.20 \%$ & $-3.87 \%$ \\
\hline 6 & $1.51 \%$ & 0 & $-2.15 \%$ & $-3.66 \%$ & $-5.98 \%$ & $-7.49 \%$ & $-3.17 \%$ & $-4.68 \%$ \\
\hline 7 & $1.51 \%$ & 0 & $-2.61 \%$ & $-4.12 \%$ & $-6.41 \%$ & $-7.92 \%$ & $-3.83 \%$ & $-5.34 \%$ \\
\hline
\end{tabular}

TABle 4. SAVIngs in Heating Demand BASEd on the Shape CoEfFICIENT AND Urban Density

\begin{tabular}{cc}
\hline Shape Coefficient $\mathbf{S c}, \mathbf{~ m}^{2} / \mathbf{m}^{\mathbf{3}}$ & Energy Conservation \\
\hline$<0.2$ & $21 \%$ \\
$0.2-0,4$ & $0 \%$ \\
$0.4-0,6$ & $-23 \%$ \\
$0.6-0,8$ & $-45 \%$ \\
$0.8-1$ & $-67 \%$ \\
$1-1.2$ & $-90 \%$ \\
\hline
\end{tabular}

\begin{tabular}{cc}
\hline Urban Density, \% & Energy Conservation \\
\hline $0-0.14$ & 0 \\
$0.15-0.29$ & $-8.88 \%$ \\
$0.3-0.44$ & $-7.12 \%$ \\
$0.45-0.59$ & $-10.04 \%$ \\
$0.6-0.74$ & $0.61 \%$ \\
$0.75-1.00$ & $13.60 \%$ \\
\hline
\end{tabular}

\subsection{Choice of the Case Study}

Annual heating demand and cost calculation model was finally applied to different case studies. The results were transferred to the energy poverty assessment method to verify its applicability and to identify the situation of 14 residential social housing buildings located in Bilbao. For the analysis, those buildings with municipal ownership of more than $75 \%$ were chosen, discarding those with less ownership since they represent a lesser capacity of intervention by the managing entity.

It was decided to analyse these buildings considering the nature of vulnerability their inhabitants are in, as being receivers of a social housing subsidy makes them eligible for the present study.

\section{RESUlts}

\subsection{Energy Poverty Assessment Method and Energy Cost Calculation Model}

Two partial results were obtained: annual heating demand and cost calculation model and adapted energy poverty assessment method for the case of Bilbao and the Autonomous Community of the Basque Country. These results were analysed with 14 case studies in Bilbao to prove their applicability. 


\subsection{Housing Vulnerability Assessment}

Different sources have been used for data collection. The average annual income was taken from the data published by Eustat for the year 2016. The area, location and year of construction have been provided by the Cadastre of Bizkaia and Alokabide respectively. An urban density of $45 \%$ was taken for the municipality of Bilbao, according to data published by Jiménez Romera [33].

The annual heating demand of each case was calculated by adjusting the result with the values of influence of the building's physical parameters per $\mathrm{m}^{2}$. Subsequently, the theoretical annual demand and the annual cost of heating for a typical dwelling in the selected building were determined. The results showed annual heating costs between $€ 250$ and $€ 560$, with annual incomes between $€ 12.387$ and $€$ 15.743. Two of the three cases with the highest heating costs correspond to districts with lower annual incomes. Moreover, those buildings identified as being in energy poverty circumstances are mainly located in vulnerable neighbourhoods.

Although the case studies, built mainly after the entry into force of the Código Técnico de la Edificación (CTE), have a similar base heating demand due to their close construction years, there are remarkable differences in the estimated annual heating demand and annual cost as a result of their reduced compactness, which considerably increases their demand. This can be observed with the analysis of cases C3, C8 and C11. The first case has a base heating demand of $31.28 \mathrm{kWh} / \mathrm{m}^{2} \mathrm{y}$ and $37.11 \mathrm{kWh} / \mathrm{m}^{2} \mathrm{y}$ for the following cases. The results in Fig. 4 shows these three cases present the highest estimated heating demand.
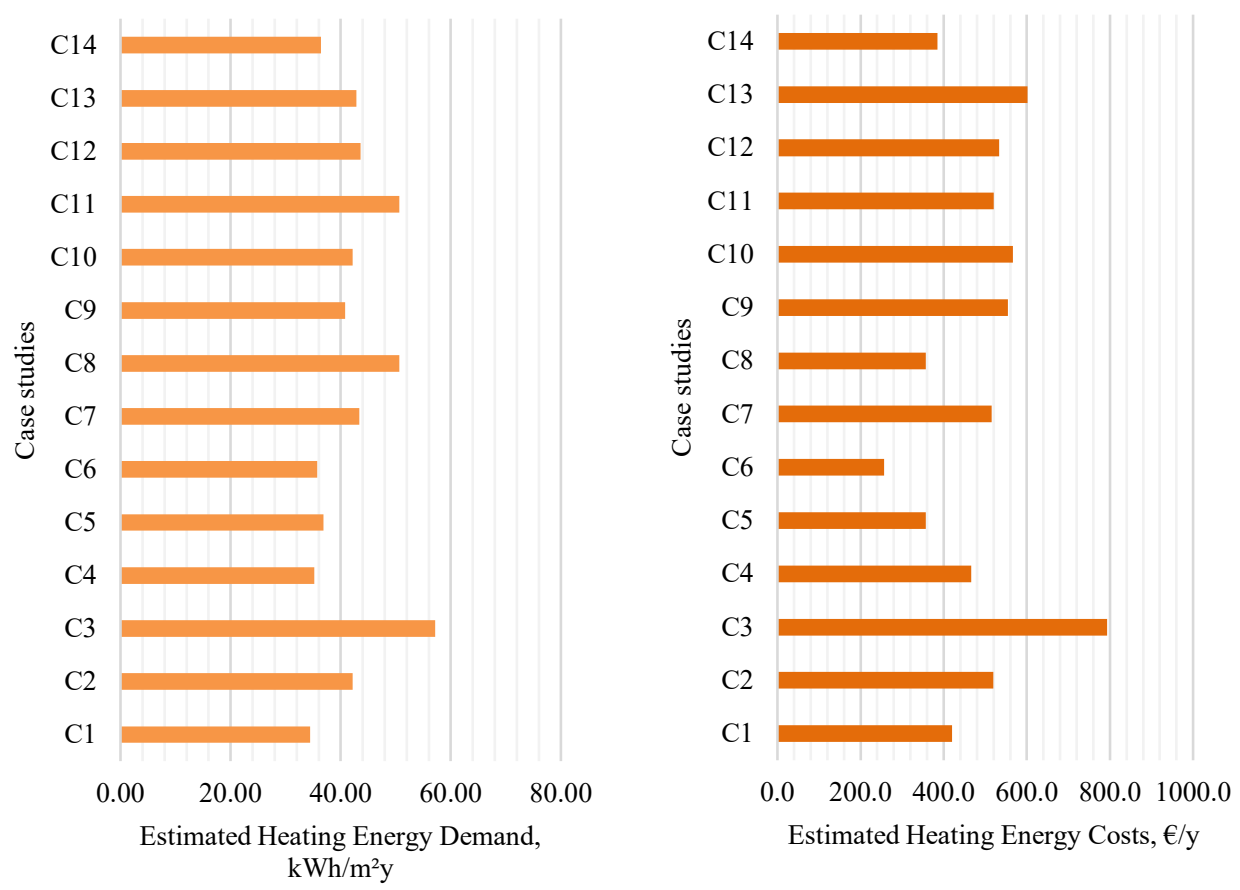

Fig. 4. Annual heating demand variation and annual heating cost variation for Bilbao case studies. 
The variation in demand and annual cost of heating is shown in Fig. 4. It shows the differences between demand and the final cost, influenced fundamentally by the surface areas of the standard dwellings in each case.

The data of estimated heating energy costs and annual equivalent income are transferred to the defined method, as shown in Fig. 5. Overall, Fig. 6 shows that the case studies analysed are in Group 3 and Group 4, in a situation of energy poverty and vulnerability to energy poverty respectively. There are two cases in Group 6, outside of any type of vulnerability.

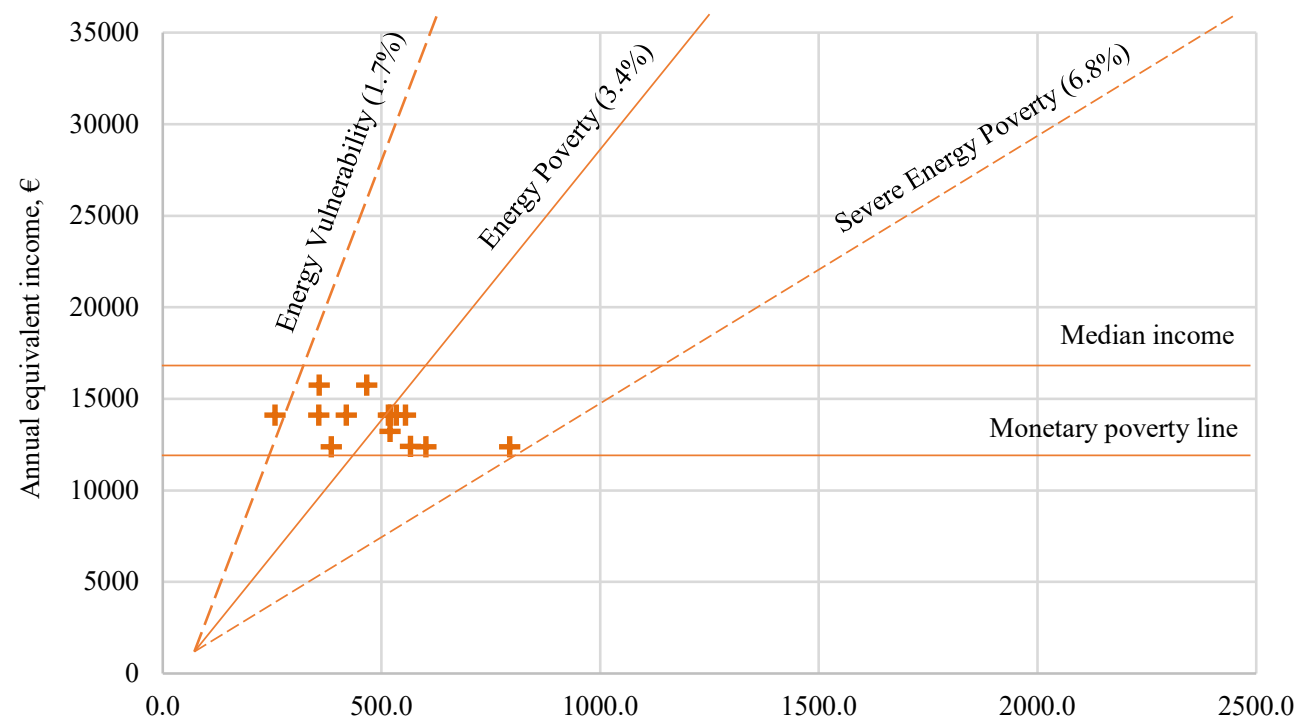

Estimated Annual Heating Energy Costs, $€$

Fig. 5. Fuel poverty assessment graph for CAPV households for 2016 [10].

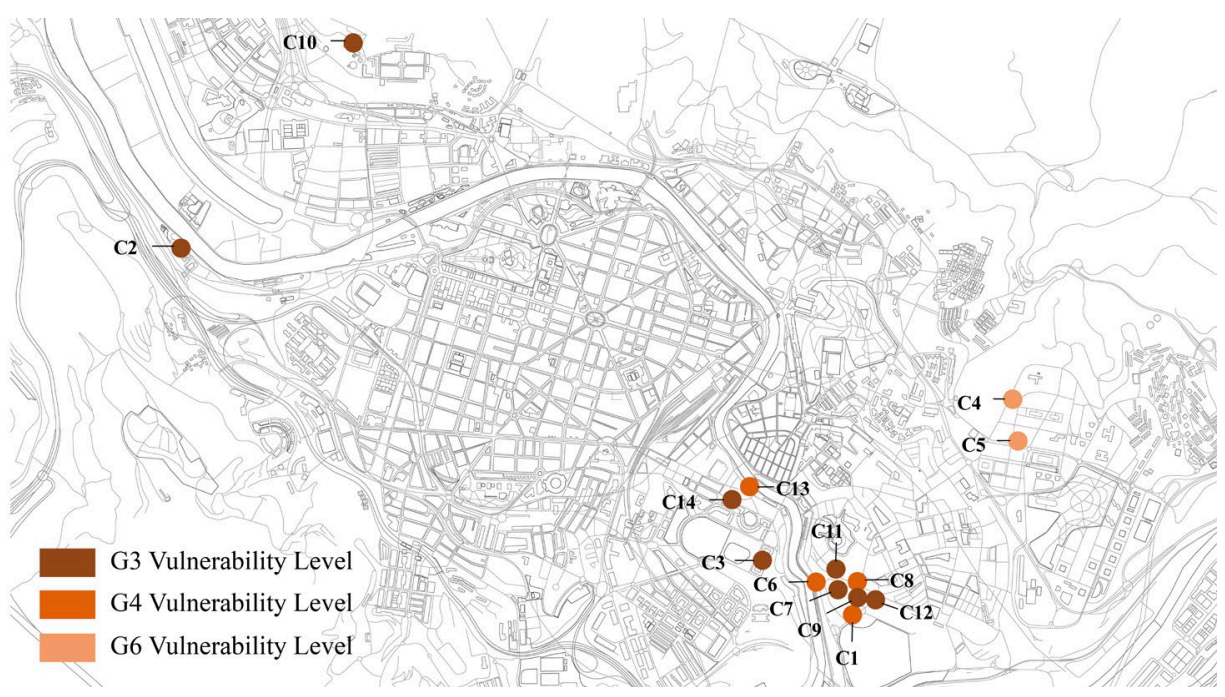

Fig. 6. Location and classification into vulnerability groups of the analysed case studies. 


\section{Conclusion}

This paper presents a proposal for prioritising the retrofitting of residential buildings in energy poverty circumstances, applied to 14 case studies in Bilbao. It has been observed that social housing complexes represent one of the most vulnerable sectors, and therefore they are notable case where refurbishment is a priority due to the socio-economic vulnerability of its residents.

The energy vulnerability assessment method proposed, allows to identify the situation of vulnerability of the analysed buildings. Measurement parameters included the particularities of each location. Therefore, a specific adjustment was developed for the case of Bilbao and the Autonomous Community of the Basque Country (CAPV).

It has been proven that compactness and year of construction are another important factor with a great impact on the demand and final consumption of heating in dwellings. The results showed annual heating costs between $€ 250$ and $€ 560$, with annual incomes between $€ 12.387$ and $€ 15.743$. Two of the three cases with the highest heating costs correspond to districts with lower annual incomes.

Some limitations of the project were detected, such as the analysed geometries, adjustment of the heating cost and the limited samples of buildings analysed. However, the main objective of the project has been achieved with the definition of a prioritization map that gave a general overview of the energy vulnerability situation of the existing social housing building stock in Bilbao. The main contribution of the research lies in acknowledging the vulnerability context of the building stock, which eases the decision-making process and the definition of intervention guidelines, prioritising those in a situation of greater vulnerability. The proposed system is accessible to different users and can serve as a tool for public entities to design their future strategies.

Since the architectural and construction typologies analysed are also representative of a city, the conclusions can be extrapolated to other national and foreign locations. Furthermore, the energy poverty evaluation graph completes the two previously defined by SánchezGuevara [10], according to the three climates included in the SECH-SPAHOUSEC project [27].

\section{ACKNOWLEDGEMENT}

We would like to acknowledge Alokabide, public corporation under the Basque Government for the development of the social function of housing through the rental policy, who has provided the necessary data for the correct definition of the study.

\section{REFERENCES}

[1] San Miguel-Bellod J., González-Martínez P., Sánchez-Ostiz A. The relationship between poverty and indoor temperatures in winter: Determinants of cold homes in social housing contexts from the 40s-80s in Northern Spain. Energy and Buildings 2018:173:428-442. https://doi.org/10.1016/j.enbuild.2018.05.022

[2] Santamouris M., Kolokotsa D. On the impact of urban overheating and extreme climatic conditions on housing, energy, comfort and environmental quality of vulnerable population in Europe. Energy and Buildings 2015:98:125-133. https://doi.org/10.1016/j.enbuild.2014.08.050

[3] HealyJ. D. Housing, Fuel Poverty and Health. Routledge, 2017.

[4] World Health Organization. Department of Housing and Urban Development, France. Ministère des affaires sociales et de la santé, and United States. Environmental Protection Agency. WHO housing and health guidelines. US: WHO, 2018.

[5] Herrero S. T. Energy poverty indicators: A critical review of methods. Indoor and Built Environment 2017:26(7):10181031. https://doi.org/10.1177/1420326X17718054 
[6] Boardman B. Fuel Poverty: from cold homes to affordable warmth. London: Belhaven Press, 1991.

[7] Boardman B. Fixing Fuel Poverty: Challenges and Solutions. London: Earthscan, 2010.

[8] Eurostat. European Commission, European Union Statistics on Income and Living Conditions (EU-SILC) [Online]. [Accessed 16.06.2019]. Available: https://ec.europa.eu/eurostat/web/income-and-living-conditions/data/database

[9] Asociación de Ciencias Ambientales (ACA). Pobreza Energética en España 2018: Hacia un sistema de indicadores y una estrategia de actuación estatal. Madrid, 2018. (in Spanish)

[10] Sánchez-Guevara Sánchez C., Neila González F. J., Hernández Aja A. Energy poverty methodology based on minimal thermal habitability conditions for low income housing in Spain. Energy and Buildings 2018:169:127-140. https://doi.org/10.1016/j.enbuild.2018.03.038

[11] Papada L., Kaliampakos D. Measuring energy poverty in Greece. Energy Policy 2016:94:157-165. https://doi.org/10.1016/J.ENPOL.2016.04.004

[12] Paravantis J. A., Santamouris M. An analysis of indoor temperature measurements in low- and very-low-income housing in Athens, Greece. Advances and Building Energy Research 2016:10(1):20-45. https://doi.org/10.1080/17512549.2015.1014842

[13] Ürge-Vorsatz D., Tirado Herrero S. Building synergies between climate change mitigation and energy poverty alleviation. Energy Policy 2012:49:83-90. https://doi.org/10.1016/j.enpol.2011.11.093

[14] Thomson, H. Thomas S., Sellstrom E., Petticrew M. Housing improvements for health and associated socio-economic outcomes. Cochrane Database Syst. Rev. 2013:2. https://doi.org/10.1002/14651858.CD008657.pub2

[15] Prodanuks et al. Analysis of Energy Supply Solutions of Dwelling Buildings. Environmental and Climate Technologies 2019:23(3):182-189. https://doi.org/10.2478/rtuect-2019-0088

[16] FilippínC., Flores Larsen S., Ricard F. Improvement of energy performance metrics for the retrofit of the built environment. Adaptation to climate change and mitigation of energy poverty. Energy and Buildings 2018:165:399 415. https://doi.org/10.1016/J.ENBUILD.2017.12.050

[17] Guerra Santin O., Itard L., Visscher H. The effect of occupancy and building characteristics on energy use for space and water heating in Dutch residential stock. Energy and Buildings 2009:41(11):1223-1232. https://doi.org/10.1016/J.ENBUILD.2009.07.002

[18] Bektas Ekici B., Aksoy U. T. Prediction of building energy needs in early stage of design by using ANFIS. Expert Systems with Applications 2011:38(5):5352-5358. https://doi.org/10.1016/j.eswa.2010.10.021

[19] Belussi L. et al. A review of performance of zero energy buildings and energy efficiency solutions. Journal of Building Engineering 2019:25:100772. https://doi.org/10.1016/j.jobe.2019.100772

[20] Elasfouri A., Maraqa R., Tabbalat R. Shading control by neighbouring buildings: application to buildings in Amman, Jordan. International Journal of Refrigeration 1991:14(2):112-116. https://doi.org/10.1016/0140-7007(91)90083-S

[21] Depecker P., Menezo C., Virgone J., Lepers S. Design of buildings shape and energetic consumption. Building and Environment 2001:36(5):627-635. https://doi.org/10.1016/S0360-1323(00)00044-5

[22] Mingfang T. Solar control for buildings. Building and Environment 2002:37(7):659-664. https://doi.org/10.1016/S0360-1323(01)00063-4

[23] Mohajeri N. et al. Effects of urban compactness on solar energy potential. Renewable Energy 2016:93:469-482. https://doi.org/10.1016/J.RENENE.2016.02.053

[24] Vermeulen T., Knopf-Lenoir C., Villon P., Beckers B. Urban layout optimization framework to maximize direct solar irradiation. Computers, Environment and Urban Systems 2015:51:1-12. https://doi.org/10.1016/J.COMPENVURBSYS.2015.01.001

[25] Salvati A., Coch H., Morganti M. Effects of urban compactness on the building energy performance in Mediterranean climate. Energy Procedia 2017:122:499-504. https://doi.org/10.1016/J.EGYPRO.2017.07.303

[26] Albatayneh A., Alterman D., Page A., Moghtaderi B. The Significance of Building Design for the Climate. Environmental and Climate Technologies 2018:22(1):165-178. https://doi.org/10.2478/rtuect-2018-0011

[27] Análisis del consumo energético del sector residencial en España. Proyecto SECH-SPAHOUSEC. 2011. (in Spanish)

[28] Instituto Nacional de Estadística. Encuesta de presupuestos familiares. Base 2006 - Año 2017 [Online]. [Accessed 17.06.2019]. Available:

https://www.ine.es/dyngs/INEbase/es/operacion.htm?c=Estadistica_C\&cid=1254736176806\&menu=ultiDatos\&idp= 1254735976608 .

[29] Bilous I., Deshko V., Sukhodub I. Parametric analysis of external and internal factors influence on building energy performance using non-linear multivariate regression models. Journal of Building Engineering 2018:20:327-336. https://doi.org/10.1016/J.JOBE.2018.07.021

[30] Jimenez-Bescos C., Oregi X. Implementing User Behaviour on Dynamic Building Simulations for Energy Consumption. Environmental and Climate Technologies 2019:23(3):308-318. https://doi.org/10.2478/rtuect-2019$\underline{0097}$

[31] Terés-Zubiaga J., Martín K., Erkoreka A., Sala J. M. Field assessment of thermal behaviour of social housing apartments in Bilbao, Northern Spain. Energy Build. 2013:67:118-135.

https://doi.org/10.1016/J.ENBUILD.2013.07.061 
[32] Grupo Consolidado de Investigación Calidad de Vida en Arquitectura. Caracterización del parque residencial de la CAPV para la elaboración de un plan de acción a largo plazo. 2018. (in Spanish)

[33] Jiménez Romera C. Tamaño y densidad urbana. Análisis de la ocupación de suelo por las áreas urbanas. Biblioteca CF+S. 2015. (in Spanish) 